\title{
RELAÇÕES ÉTNICO-RACIAIS: valores sociais e culturais na Educação Infantil
}

ETHNIC-RACIAL RELATIONS: social and cultural values in early Childhood Education RELACIONES ÉTNICO-RACIALES: valores sociales y culturales en la educación infantil

\section{Nelson Russo de Moraes}

Doutor em Comunicação e Cultura Contemporânea (UFBA), Mestre em Serviço Social pela UNESP, Graduado em Administração pela Instituição Toledo de Ensino de Bauru/SP. Professor do Curso de Graduação em Administração e do Mestrado em Agronegócio e Desenvolvimento,

nelsonrusso@tupa.unesp.br.

0000-0003-0159-9433

\section{Celenita Gualberto Pereira Bernieri}

Mestre em Sustentabilidade e Povos Tradicionais (UNB). Graduada em Pedagogia (UNITINS) e Administração Púbica (UFT). Pesquisadora de Comunidades Tradicionais, Cultura, Educação e Gestão Pública (UNESP e UNB). celecgpb@gmail.com.

\section{0-0001-6437-1538}

\section{Jardilene Gualberto Pereira Fôlha}

Mestre em Educação (UFT), Graduada em Pedagogia (UFT). Pesquisadora de Comunidades Tradicionais, Currículos Educacionais e Infâncias (UNESP e PPGE/UFT). jard-25@hotmail.com.

\section{0-0001-7216-5232}

\section{Laurenita Gualberto Pereira Alves}

Mestranda em Educação-UFT, Graduada em Normal Superior-Unitins. Pesquisadora de Comunidades Tradicionais e Infâncias. (UNESP e PPGE/UFT). laurinhagualberto25@gmail.com.

\section{0-0002-6009-2416}

Correspondência: Faculdade de Ciências e Engenharia - Câmpus de Tupã, Rua Domingos da Costa Lopes,780 - Jd. Itaipu - Tupã/SP - CEP 17602-496.

\author{
Recebido em: 12.10.2020 \\ Aceito em: 20.11.2020.
}

Publicado em: 01.01.2021.

\begin{abstract}
RESUMO:
A sociedade brasileira é multicultural, formada por vários grupos étnico-raciais, no entanto, a história de muitos desses povos é marcada por discriminações e desigualdades. A reeducação das relações étnico-raciais não é uma responsabilidade exclusiva da escola, porém, a mesma desenvolve um papel fundamental nessa luta. $\mathrm{O}$ artigo tem como objetivo estudar as relações étnico-raciais, desenvolvidas por meio dos valores sociais e culturais, que proporcionam elementos significativos para o desenvolvimento dos bebês e das crianças. A pesquisa aponta que as práticas educativas voltadas para as relações étnicoraciais favorecem às crianças momentos de vivências e experiências sobre assuntos que permeiam o cotidiano, situações que permitem internalizar atitudes de respeito a todos, independentemente das diferenças.
\end{abstract}

PALAVRAS-CHAVES: Relações ÉtnicoRaciais; Educação Infantil; Aspectos Sociais e Culturais.

\section{Introdução}

Este trabalho discute a temática das relações étnico-raciais na Educação Infantil, partindo da concepção de que o processo de desenvolvimento da criança acontece a partir de práticas significativas que fazem sentido para seu contexto educacional, histórico, social e cultural. As relações e interações são fundamentais para o desenvolvimento na infância, sendo que, é por meio das interações das crianças com outras crianças e com os adultos de etnias diferentes, que as mesmas aprendem a conviver, conhecer e respeitar as diferentes culturas e saberes que compõem a diversidade brasileira. As práticas educativas que propõem a valorização das diversas culturas e saberes fortalecem as relações étnico-raciais no contexto escolar. 
Em Brasil (2004) o sentido do termo relação étnico-racial determina que as tensas relações raciais estabelecidas no país, vão para além das diferenças na cor da pele e traços fisionômicos, mas correspondem também à raiz cultural baseada na ancestralidade afrobrasileira que difere em visão de mundo, valores e princípios da origem europeia.

A cultura, por sua vez, é formada por elementos explícitos e implícitos, Azevedo (1996) descreve-a como o conjunto de sentidos e significações, de valores e padrões, incorporados e subjacentes aos fenômenos perceptíveis da vida de um grupo social concreto, conjunto que consciente ou inconscientemente, é vivido e assumido pelo grupo como expressão própria de sua realidade humana e passa de geração em geração, conservado assim como foi recebido ou transformado, efetiva ou pretensamente pelo próprio grupo.

As relações étnico-raciais, e consequentemente as culturas, estão inclusas nos aspectos sociais e histórico-culturais que permitem à criança interpretar o mundo a partir das interações, favorecendo o desenvolvimento da aprendizagem.

Neste contexto, o principal objetivo deste estudo é, pois, estudar as relações étnicoraciais desenvolvidas por meio dos valores sociais e culturais, que proporcionam elementos significativos para o desenvolvimento dos bebês e das crianças.

Utilizou-se como recurso metodológico a pesquisa bibliográfica com abordagem qualitativa, realizada a partir da análise de materiais já publicados na literatura e artigos. O levantamento bibliográfico e documental permitiu fazer uma revisão e comparar as ideias de autores que retratam e descrevem sobre as relações étnico-raciais na Educação Infantil.

Tendo como fio condutor os estudos antropológicos relacionados à educação para as relações étnico raciais, o estudo fundamenta-se preferencialmente, nas discussões apresentadas a partir do pensamento de Munanga (2008), no qual luta contra a visão eurocêntrica e desmitificou a democracia racial no Brasil. Ao tratar das práticas culturais Azevedo (1996), Bernieri, Fôlha e Alves (2017); na mediação de aprendizagens e na construção de significados Libâneo (1996) e Kramer (2008); nos debates a respeito das intenções educativas do educador em Finco, Barbosa e Faria (2015), Hermida (2007) e Goulart (2010). Além das legislações como: a Constituição Federal (1988), Estatuto da Igualdade Racial, a Lei de Diretrizes e Bases da Educação (1996), Plano Nacional de Implementação das Diretrizes Curriculares Nacionais para Educação das Relações ÉtnicoRaciais e para o Ensino de História e Cultura Afro-brasileira e Africana (2009), Estatuto da Criança e do Adolescente e a Base Nacional Comum Curricular (2017). 


\section{Relações étnico-raciais: elementos significativos para a Educação Infantil}

A educação é direito da criança e dever do Estado, com a Constituição de 1980, tornou direito inalienável o acesso à educação das crianças de zero a seis anos de idade, conquista social importante e um grande passo para o imenso desafio brasileiro no que diz respeito à Educação Infantil. Sendo a primeira etapa da Educação Básica, a Educação Infantil tem por objetivo proporcionar aos bebês e às crianças vivências e experiências significativas com a finalidade de desenvolver a criança de maneira integral.

Finco, Barbosa e Faria (2015), explicam que é essencial que a Educação Infantil seja um espaço de práticas educativas abrangentes.

\footnotetext{
Na Constituição Federal de 1988 e na LDB/1996 a ação pedagógica com crianças de 0 a 6 anos recebeu o nome de Educação Infantil com a intencionalidade de diferir do termo ensino que antecedia as etapas Fundamental e Médio. Será um espaço que abriga ações educativas abrangentes, não apenas de conhecimentos sistematizados e organizados por áreas, mas também de saberes oriundos das práticas sociais, das culturas populares, das relações e interações, dos encontros que exigem a constituição de um tempo e um espaço de vida em comum no qual se possa compartilhar vivências sociais e pessoais. (FINCO, BARBOSA e FARIA, 2015, p. 187).
}

Desenvolver a criança integralmente é levar em consideração os aspectos sociais e culturais, nas dimensões: "físico, psicológico, intelectual e social, complementando a ação da família e da comunidade" (LDB, Art.29). Nesta perspectiva, é essencial que as práticas educativas considerem a diversidade étnica, religiosa, de gênero, social e cultural das crianças brasileiras, o que favorece a composição de propostas e projetos educativos que contemplem as necessidades das crianças e familiares.

A sociedade brasileira é formada por povos e comunidades de diversas origens culturais, o que o torna um país multicultural, sendo que as relações entre os variados grupos podem ser de harmonia, como também podem haver conflitos, em razão disso, práticas educativas relacionadas ao respeito da diversidade humana necessitam fazem parte da vida da criança desde os primeiros anos. Devido à multiculturalidade da sociedade brasileira, "surge a necessidade de promover uma educação que trate a diversidade através de uma compreensão intercultural". (BERNIERI, FÔLHA E ALVES, 2017, p. 57).

Ao observar os conflitos devido às múltiplas etnias e culturas existentes na sociedade brasileira, constata-se a urgência de as trabalhar de maneira mais sistemática em âmbito escolar. Bernieri; Fôlha e Alves (2017), defendem que a intolerância, a discriminação, o racismo e o preconceito racial constituem-se em graves problemas que 
permeiam a sociedade de um modo geral, sendo assim, o espaço escolar também é um ambiente onde esse problema se configura.

No Brasil, historicamente, o aspecto legal, manteve por muitos anos uma postura permissiva diante da discriminação e do racismo que atinge as crianças de diferentes ascendências étnico-raciais, sociais e outras. Ao analisar os dados de pesquisas brasileiras que apontam as desigualdades entre as etnias, constata-se a necessidade urgente de inserir práticas educativas e novas metodologias de ensinar a respeito da diversidade humana desde os primeiros anos de vida da criança. A Constituição Federal (1998) declara que todos são iguais perante a lei, sem distinção de qualquer natureza. A mesma constitui princípio fundamental da República Federativa do Brasil o de promover o bem comum, sem preconceitos de origem, raça, sexo, cor, idade ou quaisquer outras formas de discriminação.

O Estatuto da Criança e do Adolescente (1991), garante o direito à liberdade, ao respeito e a dignidade das pessoas humanas no processo de desenvolvimento, como sujeitos de direitos civis, humanos e sociais, bem como o direito à educação, visando o pleno desenvolvimento da pessoa, o preparo para o exercício da igualdade de condição para o acesso e permanência na escola; direito de ser respeitado por seus educadores; e ter respeitado os valores culturais, artísticos e históricos próprios no contexto social da criança e do adolescente, garantindo-se a este a liberdade de criação e o acesso às fontes culturais.

Para fortalecer o ensino sobre a cultura do povo afro-brasileiro, foi aprovado o Plano Nacional de Implementação das Diretrizes Curriculares Nacionais para Educação das Relações Étnico-Raciais e para o Ensino de História e Cultura Afro-Brasileira e Africana (2009), o plano concorda que os desafios da qualidade e da equidade na educação só serão superados se a escola for um ambiente acolhedor, que reconheça e valorize as diferenças e não as transforme em fatores de desigualdade. Garantir o direito de aprender, implica em fazer da escola um lugar em que todos e todas sintam-se valorizados e reconhecidos como sujeitos de direito em sua singularidade e identidade.

O papel da Educação Infantil é significativo para o desenvolvimento humano, a formação da personalidade, a construção da inteligência e a aprendizagem. Os espaços coletivos educacionais, nos primeiros anos de vida, são espaços privilegiados para promover a eliminação de qualquer forma de preconceito, racismo e discriminação, fazendo com que as crianças, desde muito pequenas, compreendam e se envolvam conscientemente em ações que conheçam, reconheçam e valorizem a importância dos diferentes grupos étnico-raciais para a história e a cultura brasileiras. (BRASIL, 2009, p. 49). 
As instituições de ensino têm uma responsabilidade decisiva para o fortalecimento das relações étnico-raciais, sua função é para além da educação formal, contempla também formação pessoal e social. Favorece a oportunidade de conhecer outros grupos de bebês e de crianças, para que possam conhecer e respeitar as diferentes culturas e modos de vida. Permite o conhecer dos valores sócio-históricos, étnicos e culturais por meio de experiências significativas que fazem sentido para as crianças, e torna-se uma condição positiva para a ensiná-las a viver em sociedade.

A criança, de acordo com as Diretrizes Curriculares Nacionais para a Educação Infantil-DCNEI (2009), é considerada como um sujeito ativo e que produz cultura.

\footnotetext{
Sujeito histórico e de direitos que, nas interações, relações e práticas cotidianas que vivencia, constrói sua identidade pessoal e coletiva, brinca, imagina, fantasia, deseja, aprende, observa, experimenta, narra, questiona e constrói sentidos sobre a natureza e a sociedade, produzindo cultura. (BRASIL, 2009, p. 12).
}

A criança como sujeito histórico e de direitos necessita conhecer, conviver e explorar a sua cultura e do grupo que está inserida: modo de vida, bagagens culturais, interesses individuais e de sua comunidade, situações que contribuem para a construção da identidade pessoal, social e cultural.

A Base Nacional Comum Curricular (2017) pode ser compreendida como um documento plural, contemporâneo e que estabelece com clareza o conjunto de aprendizagens essenciais e indispensáveis a que todos os estudantes têm direito. A BNCC expressa o compromisso do Estado Brasileiro "com a promoção de uma educação integral voltada ao acolhimento, reconhecimento e desenvolvimento pleno de todos os estudantes, com respeito às diferenças e enfrentamento à discriminação e ao preconceito". (BRASIL, 2017, p. 04)

A partir das legislações, vêm sendo estabelecidas garantias para que os bebês e as crianças possam brincar, participar, explorar, expressar e conhecer-se por meio de vivências e experiências educativas que considerem a diversidade étnica. Entretanto, verifica-se que o processo de ensino, adotado pelos profissionais contemporâneos, ainda não foi suficiente para internalizar a questão da diversidade de maneira significativa à prática. Isto porque grande parte dos educadores da sociedade brasileira não adquiriram em sua formação o necessário preparo para trabalhar com os desafios que existem na convivência com a diversidade e as expressões de discriminação. Professores, pais e estudantes de maneira geral são frutos de uma educação eurocêntrica, em consequência desta, reproduz-se, muitas vezes conscientemente ou inconscientemente, os preconceitos que estão na sociedade. 


\begin{abstract}
Observa-se que, oferecer uma educação para a diversidade ainda é um desafio para o Estado e para os profissionais da educação. Dentre as várias dificuldades encontradas na educação e no cuidado com as crianças, encontra-se a necessidade de adotar práticas educativas que contemplem a diversidade brasileira e alcancem resultados positivos e significantes. Grande parte dos educadores continua com práticas educativas ultrapassadas, ao invés de construir maneiras coletivas, novas formas de convivência e respeito entre educadores, crianças e comunidade. (ROCHA \& FÔLHA, 2017, p.34)
\end{abstract}

Muitas escolas ainda trabalham com literaturas e brinquedos que representam apenas parte dos bebês e das crianças. Vale ressaltar ainda que, várias literaturas, quando apresentam um personagem de diferentes ascendências étnico-raciais, expõem de forma estereotipada e caricatural, despossuídos de humanidade e cidadania. Literaturas como estas, fortalecem as práticas de desrespeito ao próximo e perpetuam as mais diversas formas de racismo, discriminação e intolerância. Quando a literatura infantil é utilizada de modo adequado se torna um instrumento importante na construção do conhecimento da criança, e faz com que ela desperte para o mundo da leitura como um ato de aprendizagem significativa. Venturini (2017) ressalta que uma providência essencial é adquirir materiais didáticos que valorizem as diferenças culturais, os procedimentos metodológicos podem ser hora do conto, confecção de bonecos, e compete à escola orientar sua equipe, de forma a desenvolver o princípio filosófico do pluralismo no pensamento, de conteúdo ético e político, que deve funcionar como antídoto à manutenção de práticas reducionistas que limitam, inferiorizam e excluem, como o racismo.

Tanto a leitura como o brincar, educam e estimulam o desenvolvimento da atenção, imaginação, observação, memória, reflexão e linguagem dos bebês e das crianças. Nesta perspectiva, é importante que os brinquedos pedagógicos e livros representem a diversidade, o que favorece as crianças atitudes mais inclusivas e a aceitação das diferenças. Para as crianças se identificarem com bonecas de diferentes tipos, fortalecerem a própria identidade e valorizarem a si e ao próximo. Durante o brincar, a criança aprender a conviver com a diversidade social, e consequentemente, torna-se um adulto preparado para viver em sociedade.

Torna-se necessário ao educador buscar ou construir de maneiras coletivas, novas formas de convivência e respeito entre educadores, alunos e comunidade. Para trabalhar as relações étnico-raciais em sala de aula é preciso conhecer para entender e respeitar, é aceitar a colaboração das inúmeras culturas, vindas das diversas matrizes culturais presentes na sociedade. Neste sentido, Munanga (2008) afirma que se torna necessário 
refletir até que ponto as culturas oriundas dos grupos subordinados na sociedade, cujas contribuições não são consideradas como tradição e passado significativo e, por isso, são invisibilizadas e minimizadas nos currículos, poderão vir a ser objeto de investigação e constituir-se na prática educativa dos professores. Por outro lado, os sujeitos dessas culturas são representados, em grande parte, nos meios de comunicação e materiais pedagógicos, sob forma estereotipada e caricatural, despossuídos de humanidade e cidadania.

Para Libâneo (1996), não há sociedade sem prática educativa, nem prática educativa sem sociedade. A prática educativa não é apenas uma exigência da vida em sociedade, mas também o processo de prover os indivíduos dos conhecimentos e experiências culturais que os tornam aptos a atuar no meio social, e a transformá-lo em função de necessidades econômicas, sociais e políticas da coletividade. Libâneo (1996) ainda destaca a influência que possui a prática educativa sobre os indivíduos e afirma que:

\begin{abstract}
Através da ação educativa o meio social exerce influência sobre os indivíduos e estes, ao assimilarem e recriarem essas influências, tornamse capazes de estabelecer uma relação ativa e transformadora em relação ao meio social. Tais influências se manifestam através de conhecimentos, experiências, valores, crenças, modos de agir, técnicas e costumes acumulados por muitas gerações de indivíduos e grupos, transmitidos, assimilados e recriados por novas gerações. (LIBÂNEO, 1996, p. 15).
\end{abstract}

Quando a criança começa a vida escolar, amplia o seu universo, uma vez que o contato com outras crianças e com educadores, que possuem origens e hábitos culturais diversos, proporciona oportunidades de aprender novas brincadeiras, conhecer pessoas e espaços e de adquirir conhecimentos sobre diferentes realidades. Segundo Goulart (2010) as primeiras experiências são as que marcam mais profundamente a pessoa, e quando positivas, tendem a reforçar, ao longo da vida, as atitudes de autoconfiança, de cooperação, solidariedade, responsabilidade.

A atuação do educador é fundamental para que os bebês e as crianças adquiram oportunidades de experiências estimuladoras que possibilitem construir o seu próprio conhecimento, levando em consideração as suas características étnicas, religiosas, econômicas e social. A BNCC (2017) defende que pelas experiências as crianças podem ampliar o modo de perceber a si mesmas e ao outro, valorizar sua identidade, respeitar os outros e reconhecer as diferenças que nos constituem como seres humanos. Ressalta que na Educação Infantil, é preciso criar oportunidades para que as crianças entrem em contato com outros grupos sociais e culturais, outros modos de vida, diferentes atitudes, técnicas e rituais de cuidados pessoais e do grupo, costumes, celebrações e narrativas. 
É importante que as relações étnicos-raciais sejam introduzidas nas experiências educativas na Educação Infantil de maneira lúdica, por meio das interações e brincadeiras, para que as crianças possam entender as contribuições de todas as etnias para a sociedade. Nesta perspectiva, Munanga (2008) descreve sobre a importância de todos os grupos étnicos para formação da identidade brasileira, e ainda ressalta que a superação do racismo e intolerância no país é uma tarefa de urgência.

\begin{abstract}
É indispensável que reflitam, em sua plenitude, as contribuições dos diversos grupos étnicos para a formação da nação e da cultura brasileiras. Ignorar essas contribuições - ou não lhes dar o devido reconhecimento - é também uma forma de discriminação racial (...). A superação do racismo ainda presente em nossa sociedade é um imperativo. É uma necessidade moral e uma tarefa política de primeira grandeza. E a educação é um dos terrenos decisivos para que sejamos vitoriosos nesse esforço. (MUNANGA, 2008 p.11).
\end{abstract}

Para os educadores, educar, cuidar e brincar, com os bebês e as crianças de 0 a 5 anos, supõem definir previamente como serão feitas e desenvolvidas as práticas pedagógicas, objetivando a inclusão das crianças e das famílias em uma vida de cidadania. Da mesma forma Hermida (2007) acredita que para desempenhar, a contento, a mediação de aprendizagens na construção de significados, o educador necessita conhecer como as crianças pensam e se apropriam dos conhecimentos, para saber intervir no sentido de que elas possam avançar. A mesma autora ainda afirma que é fundamental que o profissional tenha clareza e consciência quanto às intenções educativas que norteiam seu trabalho, e elabore propostas claras sobre o que, quando e como ensinar, a fim de possibilitar atividades de ensino e aprendizagem de maneira adequada e coerente com seus objetivos, enriquecendo e promovendo o desenvolvimento das crianças.

Munanga (1998) acredita que a falta de preparo dos professores está relacionada com o mito da democracia racial que compromete, sem dúvida, o objetivo fundamental da nossa missão no processo de formação dos futuros cidadãos. E destaca que "não podemos esquecer que somos produto de uma educação eurocêntrica e podemos, em função desta, reproduzir consciente ou inconscientemente os preconceitos que permeiam nossa sociedade" (MUNANGA, 1998, p. 15)

De acordo com Kramer (2011), as crianças como seres sociais que são, têm uma história, pertencem a uma classe social, estabelecem relações segundo seu contexto de origem, têm uma linguagem, ocupam um espaço geográfico e são valorizadas de acordo com os padrões do seu contexto familiar e com a sua própria inserção nesse contexto. Elas são pessoas, enraizadas num todo social que as envolve, e que nelas imprime padrões de autoridade, linguagem, costumes. Sobre a postura do educador, Kramer (2011) diz que 
o desafio maior é um olhar e uma escuta sensível, entender a linguagem para além do que é dito, compreender significados do corpo e movimentos, tensões e apreensões, sentidos do choro, do riso, de disputas, demonstrações de carinho, raiva, partilha.

Neste mesmo sentido, Libâneo (1996) destaca alguns aspectos importantes para os professores, como: conhecer estratégias de ensinar a pensar e ensinar a aprender; mediar os alunos a buscarem uma perspectiva crítica dos conteúdos, atender a diversidade cultural e respeitar as diferenças no contexto da escola.

É indispensável que a instituição de ensino desenvolva atividades que se fundamentem em princípios de educação, relacionadas com os interesses e necessidades da criança, dando prioridade à aprendizagem por meio da solução de problemas, ação educativa ligada à vida, o incentivo da solidariedade e a tolerância entre as crianças. Nesta perspectiva, Barbosa e Finco, Barbosa e Faria (2015) afirmam que o professor, com seu olhar de quem está com a criança, mas também com os saberes e conhecimentos, realiza a complexa tarefa educacional de possibilitar encontros, de favorecer interações lúdicas, constituir tempos e espaços para a experiência das crianças, sem nenhuma garantia de que essa possa acontecer.

Neste seguimento, a BNCC (2017) alerta as instituições que atendem a infância para que, por meio do diálogo, possam proporcionar práticas que contemplem a diversidade cultural.

(...) para potencializar as aprendizagens e o desenvolvimento das crianças, a prática do diálogo e o compartilhamento de responsabilidades entre a instituição de Educação Infantil e a família são essenciais. Além disso, a instituição precisa conhecer e trabalhar com as culturas plurais, dialogando com a riqueza/diversidade cultural das famílias e da comunidade. (BRASIL, 2007, p.34).

Munanga (2008) afirma que a escola, como parte integrante dessa sociedade que se sabe preconceituosa e discriminadora, mas que reconhece que é hora de mudar, está comprometida com essa necessidade de mudança, e precisa ser um espaço de aprendizagem onde as transformações devem começar a ocorrer de modo planejado e realizado coletivamente por todos os envolvidos, de modo consciente.

Um conjunto de forças precisa ser somadas para alcançar as transformações, nesta perspectiva, atores como o estado, a sociedade civil organizada, educadores e a academia são indispensáveis no processo. Nesse sentido, concorda-se com Lima \& Trindade (2009), que apontam a formação continuada de educadores e as pesquisas voltadas para a temática como necessárias para o desenvolvimento saudável de uma sociedade multicultural. 
A formação continuada e as pesquisas voltadas para as africanidades e afrodescendência precisam fazer de fato parte das preocupações políticas dos órgãos oficiais e da sociedade civil organizada, de modo a instituir esta temática como significativa e prioritária para a efetivação concreta de uma educação brasileira para todos. (LIMA \& TRINDADE, 2009, p. 35)

A fim de que as políticas públicas voltadas para as questões étnico-raciais, e consequentemente a valorização dos aspectos sociais e culturais, sejam alcançadas se faz necessário que toda a equipe escolar sinta valorizada e apoiada, entretanto ainda não é satisfatória a obrigatoriedade da lei se o Estado não disponibiliza condições de formação profissional àqueles que fazem parte da comunidade escolar e que trabalham diretamente com as crianças.

Sabe-se que a educação escolar, ainda que não consiga resolver sozinha, no entanto, ocupa um espaço de destaque nesta luta. Partindo da tomada de consciência dessa realidade, sabemos que nossos instrumentos de trabalho na escola e na sala de aula, isto é, os livros e outros materiais didáticos visuais e audiovisuais, carregam os mesmos conteúdos viciados, depreciativos e preconceituosos em relação aos povos e culturas não oriundos do mundo ocidental. Os mesmos preconceitos permeiam também o cotidiano das relações sociais de alunos entre si, e de alunos com professores no espaço escolar (MUNANGA, 2008, p. 15).

A educação é a principal ferramenta de transformação social, sendo assim, o educador propicia condições para que os bebês e as crianças desenvolvam sua capacidade dialógica, conheçam as raízes históricas que constituem a cultura brasileira e construam sua identidade pessoal, cultural e social.

\section{Considerações}

Por fim, verifica-se que as legislações que promovem as relações étnico-raciais vêm sendo estabelecidas, entretanto, os processos de fortalecimento das práticas educativas nas escolas ainda não são suficientes para internalizar a questão da sociedade multicultural de maneira significativa. O espaço de aprendizagem propício para abrolhar as transformações que se espera da sociedade, necessita de um conjunto de forças articuladas por parte do estado, da sociedade civil organizada, da academia e da comunidade escolar.

A pesquisa destaca que as práticas educativas, voltadas para as relações étnicoraciais, favorecem os bebês e às crianças momentos de vivências sobre assuntos que permeiam o cotidiano, situações que permitem internalizar atitudes de respeito a todos, independentemente das diferenças. 
O processo de desenvolvimento das relações étnico-raciais na Educação Infantil acontece quando as instituições, juntamente com os educadores, promovem uma educação ética, voltada para o respeito e convívio harmônico. É essencial que o cotidiano escolar ofereça experiências pelas quais os bebês e as crianças possam conhecer e valorizar os conhecimentos historicamente construídos, as diversas manifestações artísticas e culturais e a diversidade de vivências culturais e saberes. Assim como, exercitar o diálogo, a empatia, a resolução de conflitos e a cooperação, para que o respeito ao próximo possa ser uma prática constante desde os primeiros anos de vida da criança.

\section{Referências}

AZEVEDO, M. Comunidades eclesiais de base e inculturação da fé. São Paulo: Loyola, 1996.

BERNIERI, Celenita; FÔLHA, Jardilene; ALVES, Laurenita. Relações Étnico-Raciais e Interculturalidade na Educação Infantil. In: II INTERFOR, VII ENFORSUP - UFT, 12 a 15 de setembro de 2017, Palmas, TO. Anais (on-line). Disponível em: < https://docs.uft.edu.br/share/s/3iMMPL_wRISw597jz_UE-w>. Acesso em: 25 de agosto de 2020.

BRASIL. Ministério da Educação. Diretrizes Curriculares Nacionais para a Educação das Relações Étnico-raciais e para o Ensino de História e Cultura Afro-brasileira e Africanas. Brasília: Secad/MEC, 2004. Disponível em: <http://www.acaoeducativa.org.br/fdh/wp-content/uploads/2012/10/DCN-sEducacao-das-Relacoes-Etnico-Raciais.pdf>. Acesso em: 24 de agosto de 2020.

BRASIL. Presidência da República. Constituição da República Federativa do Brasil: promulgada em 5 de outubro de 1988. Brasília, DF. Disponível em: <http://www.planalto.gov.br/ccivil_03/constituicao/ConstituicaoCompilado.html>. Acesso em: 28 de agosto de 2020.

. Ministério da Educação. Base Nacional Comum Curricular. Disponível em: < http://basenacionalcomum.mec.gov.br/download-da-bncc >. Acesso em: 30 de agosto de 2020.

. Ministério da Educação. Diretrizes Curriculares para Educação Infantil. Disponível em: <http://www.planalto.gov.br/ccivil_03/leis/19394.htm>. Acesso em: 30 de agosto de 2020.

. Ministério da Educação. Lei de Diretrizes e Bases da Educação Nacional n 9394 de 20 de dezembro de 1996. Disponível em:

<http://www.planalto.gov.br/ccivil_03/leis/19394.htm>. Acesso em: 26 de agosto de 2020. . Lei n.8.069 de 13 de julho de 1990. Estatuto da Criança e do Adolescente. Disponível em: <http://www.planalto.gov.br/ccivil_03/leis/L8069.htm>. Acesso em: 29 de agosto de 2020.

BRASIL. Lei $n^{\circ} 12.288$ de 20 de julho de 2010. Estatuto da Igualdade Racial. Disponível em <http://www.planalto.gov.br/ccivil_03/_Ato2007-2010/2010/Lei/L12288.htm > . Acesso em: 29 de agosto de 2020.

GOULART, Isabelly. A Importância da Educação Infantil na Formação do Cidadão Crítico/Reflexivo. Disponível em <http://pedagogia.com.br/artigos/criticoreflexivo/>. Acesso em: 27 de agosto de 2020.

HERMIDA, J. F. (org.) Educação Infantil: políticas e fundamentos. 1 ed. João Pessoa: Editora Universitária da UFPB, 2007. 
FINCO, Daniela; BARBOSA, Maria Carmen; FARIA, Ana Lucia Goulart. Campos de experiências na escola da infância: contribuições italianas para inventar um currículo de educação infantil brasileiro. Campinas, SP: Edições Leitura Crítica, 2015.

KRAMER, Sonia. O papel social da educação infantil (1), 2008. Disponível em:<http://www.dominiopublico.gov.br/download/texto/mre000082.pdf $>$. Acesso em: 27 de agosto de 2020.

LIMA, Maria Batista; TRINDADE, Azoilda Loretto da. Africanidades, currículo e formação docente: desafios e possibilidades. In: MELO, Maros Ribeiro de; LIMA, Maria Batista; LOPES, Edinéia Tavares (Orgs.). Identidades e alteridades: debates e práticas a partir do cotidiano escolar. São Cristóvão: Editora UFS, 2009.

LIBÂNEO, José Carlos. Didática. São Paulo: Cortez, (Coleção magistério Série Formação do professor). 2008.

MUNANGA, Kabengele (org). Superando o racismo na escola. Brasília: MEC/SECAD, 2008.

MUNANGA, Kabengele. Negritude: Usos e sentidos. São Paulo: Ática, 1998.

ROCHA José Damião; FÔLHA, Jardilene. Participação política nas práticas educativas das diversidades e relações étnico-raciais desenvolvidas em CMEI'S palmenses. In: VI Seminário Contemporâneo do Programa de Pós-Graduação em Educação - UFT, 2017, Palmas, TO. Anais (on-line). Disponível em: <https://pt.scribd.com/document/376272445/Anais-VI-Seminario-PPGE-2017-2pdf $>$. Acesso em: 26 de agosto de 2020.

VENTURINI, Andressa. As relações étnico-raciais na educação infantil. Universidade Federal de Santa Maria, 2015.

\begin{abstract}
:
Brazilian society is multicultural, formed by several ethnic-racial groups, however, the history of many of these peoples is marked by discrimination and inequality. The reeducation of ethnic-racial relations is not an exclusive responsibility of the school; however, it plays a fundamental role in this struggle. Educational practices that promote the valuation of several cultures and knowledge strengthen ethnic-racial relations in the school context, especially if they are promoted from the first years of the child's life. The article aims to study ethnic-racial relations, developed through social and cultural values, which provide significant elements for the development of babies and children. The research points out that educational practices focused on ethnicracial relations favor to the children moments of experiences on subjects that permeate everyday life, situations that allow internalizing attitudes of respect for everyone, regardless of differences.
\end{abstract}

KEYWORDS: Ethnic-Racia Relations; Early Childhood Education; Social and Cultural Aspects.

\begin{abstract}
RESUMEN:
La sociedad brasileña es multicultural, formada por varios grupos étnico-raciales, sin embargo, la historia de muchos de estos pueblos está marcada por la discriminación y la desigualdad. La reeducación de las relaciones étnico-raciales no es una responsabilidad exclusiva de la escuela, sin embargo, desarrolla un papel fundamental en esta lucha. El artículo pretende estudiar las relaciones étnico-raciales, desarrolladas a través de los valores sociales y culturales, que proporcionan elementos significativos para el desarrollo de los bebés y los niños. La investigación señala que las prácticas educativas centradas en las relaciones étnico-raciales proporcionan a los niños momentos de experiencias sobre temas que impregnan su vida cotidiana, situaciones que les permiten interiorizar actitudes de respeto hacia todos, independientemente de las diferencias.
\end{abstract}

PALABRAS-CLAVES: Relaciones ÉtnicoRaciales; Educación Infantil; Aspectos Sociales y Culturales. 